intended outcomes desired. For example, there is evidence that sustainable agriculture, and even organic farming, can be implemented more profitably by large farming operations instead of the "family farms" advocated by many in the sustainable agriculture community.

A famous psychologist once said that it is difficult to get one's "NO" back. Every time one abrogates social responsibility by turning to government to redress problems, one has removed power from him or her self to control and direct his/her life and that of the local community. The Canadians might wish to tread lightly until they see how the recent legislation in the United States plays out in program implementation with regards to organic and sustainable agriculture.

Tom P. Abeles, Ph.D.

President

I. E. Associates, Inc.

3704 - 11th Avenue South

Minneapolis, MN 55407

Response: I like some of the thoughts put forward by Abeles but am confused by others.

Abeles alludes to some interesting questions regarding the relationship between policy that respects agroecological principles and the homogeneity of the population. We did not discuss this in our paper, but it would be most interesting to see a conceptual analysis of whether public policy that supports agroecological diversity can satisfy the needs of an ethno-racially diverse population.

I also like Abeles' conclusions on the need for more thinking on new farm and rural community models. I don't believe, however, that our analysis implies preserving existing models. To hold such a position would be a contradiction of basic ecological principles. Nor do we conclude that only small and family farms can produce food sustainably. Although we did not discuss it at length, the regional land use implications of a policy of food self-reliance imply very different patterns of agricultural production, processing and distribution, and very different intracommunity dynamics. This is a very important area for further work.
It is not clear to me how the author has come up with his interpretation of our trade analysis. We are not saying that there shouldn't be trade, but rather that international and interregional trade should respect ecological principles. Simply stated, once a region has satisfied (in an economic and biophysical sense) its own markets, excess can be exchanged with other areas. Canadian trade and trade policy have never been designed around this idea.

Finally, Abeles misinterprets the reason for focusing our discussion on the role of government in the transition to sustainable systems. We are definitely not saying that government has the only role to play in this process. Community and farm organizations must actively push governments to change their agricultural agenda. We believe our paper serves as a "road map" for the political work of these organizations.

Rod MacRae

\section{Questions experimental design}

"The on-farm research program of Practical Farmers of Iowa" [Volume 5(4)] focuses on experimental design and analysis, yet several astonishing errors occur in the paper.

Someone must have been sleeping to allow the figure on page 164 to go uncorrected. The drawing illustrates no replication, rather than three replicates, as stated in the legend.

The paper states that 6 or more replications are needed in this design. Such general statements are misleading. The number of replications required to detect significant differences is dependent on 1) the magnitude of differences between treatments, 2) the amount of variation among replicates, 3) the desired significance level, and 4) depending on one's philosophy of comparison, the number of treatments in the experiment. How could such a blanket statement go unchallenged?

When referencing the figure, the authors use the terms "blocks," "replicates," and "pairs" interchangeably. The analysis of the data will be different depending on the exact grouping of the treatments. If the treatments are arranged in true blocks or if more than two treatments are used, then an analysis of variance using F-tests is called for. If the treatments are grouped in pairs, then a paired t-test would be most appropriate.

Finally, the implication is made that long strip plots are suitable for all onfarm experiments. In the case of variety trials or herbicide tests, there are certain advantages. However, in the case of insect or disease management trials, large square plots may be more desirable since the target organism or management technique may not be static in space or time.

I am extremely pleased to read articles by farmers in $A J A A$, but in this particular case, some guidance from a competent reviewer was called for.

Marvin P. Pritts

Associate Professor

Extension Specialist

Department of Fruit

and Vegetable Science

Cornell University

Ithaca, NY 14853-0327

Response: As the authors of the paper in question, and as technical editor responsible for its review, we appreciate Professor Pritts' taking the trouble to point out possible errors. However, we believe that, on closer examination, only one of his criticisms really qualifies as an error: the technical editor readily admits to somnolence in not catching the "Three Replications" legend, which should have read "Three Treatments."

The sentence about 6 or more replications being needed was not intended as a general statement. The right number of replications certainly does depend on all the things that Professor Pritts lists. In the paper, the statement in question was immediately followed by typical values of those very parameters (significance level, number of treatments, variance, etc.) for the experiments under discussion. We thought the statement would be understood in that light; that is, it obviously was intended to be taken in the context of the entire paragraph, not as a "blanket statement." Perhaps this would have 
been clearer if instead of saying "in this design" the statement had read "for these experiments."

The argument about analysis of variance and an F-test being appropriate if there are more than two treatments, whereas a paired $t$-test is appropriate for two treatments, overlooks an important point: with two treatments, analysis of variance and a paired t-test are identical. The F-statistic in such a case is simply the square of the t-statistic, and the statistical significance of the observed difference between treatments is the same, regardless of which way it was computed.

Finally, the statement about the suitability of long strips was certainly not intended to refer to all on-farm experiments. In the paper, that statement began by citing the particular methodological research on which it is based. We took for granted that the reader would know to supply the qualifier "under the conditions of that research." (Not coincidentally, that research dealt with experiments similar to those discussed in the paper.) One might argue that such a qualifier should always be included when citing a research result, but commonly it is left unsaid, without causing any great misunderstanding.

Richard Thompson

Sharon Thompson

William Lockeretz

\section{A sustainable agriculture requires broad approach}

The commentary by Allen et al., Integrating social, environmental, and economic issues in sustainable agriculture (Volume 6, No. 1, page 34) was great. They clearly pointed out the existing imbalance between the search for specific on-farm strategies and the search for social, political, and economic structure for a sustainable agriculture. Lots of the former, little of the latter in our mainstream agricultural establishment.

Cultural, political, social, and ethical foundations for a sustainable agriculture have continuously been proposed by Wendell Berry, Wes Jackson, Marty
Strange, Gene Logsdon, Donald Worster, Gary Nabhan, Robert Rodale.... These scholars have thoroughly outlined the basic assumptions that have lead (and are still leading) agriculture to its current degrading path, raised essential questions, and wrote about possibilities for an agriculture that cares for the land and the people. Many of us working to create a healthier agriculture have been inspired by them and yet, for some reason, they are not acknowledged in the cited literature by Allen et al. or many other papers related to rethinking of our agriculture, integrating sociology, ethics, and justice in agriculture.

The ultimate measure of the quality and effectiveness of our agricultural research, education, and service should be reflected in farmers' livelihood, resurrected rural communities, landscape restoration, and social and economic equity for people in the food system here and elsewhere.

Kamyar Enshayan, Ph.D.
Sustainable Agriculture
Program
The Ohio State University
Columbus, OH 43210-1220

Response: Dr. Enshayan is quite right in citing the contributions of these writers--they have been among the first to influence the agricultural paradigm in the direction of sustainability. Our article was not intended as a comprehensive literature review, however, but an attempt to demonstrate that we need to move beyond the priorities of many sustainable agriculture programs newly established within agricultural institutions. Nonetheless, while we also acknowledge the seminal contributions of Berry, Jackson, Strange, et al., we think we need to go farther than they do in reconstructing agriculture in ways that will make it truly sustainable for all social groups. Their work focuses on the traditional American family farm as the beneficiary and ideal vehicle for sustainability. While this is an important focus, we believe it does not adequately encourage new agricultural forms that address the issues of the larger community which is a part of agriculture and is affected by it. Partic- ularly overlooked is the need to reconfigure race, class, and gender relations in ways that allow everyone--including women, people of color, the poor--to benefit equally from sustainable agriculture. This theme is elaborated in an article by Patricia Allen and Carolyn Sachs in issue 13 of the journal Science as Culture.

Patricia Allen, Debra Van Dusen, and Stephen Gliessman

\section{Supreme Court Allows Localities to Regulate Pesticides}

The U.S. Supreme Court has ruled unanimously that the Federal Insecticide, Fungicide, and Rodenticide Act (FIFRA) does not deny local authorities the right to regulate pesticides. However, the Supreme Court reaffirmed the right of states to pre-empt local authority, if they choose; states that do not already have laws concerning local pesticide authority may now tackle the issue. The decision applies only to local regulation of the use and sale of pesticides, not labeling, packaging, or initiation of health studies. The case began in 1985 when a Christmas tree grower in Casey, Wisconsin, was denied a permit for aerial spraying of pesticides on some of his land and sued the local government. 